\title{
A study on expression levels of matrix metalloproteinases and their inhibitors in patients with ulcerative colitis
}

\author{
Guo-Dong Huang ${ }^{1}$ and Jing Xiong ${ }^{2 *}$ \\ ${ }^{1}$ Department of Integrated Traditional Chinese Medicine and Western Medicine, ${ }^{2}$ Cadre's Ward, The First Affiliated Hospital of \\ Nanchang University, Nanchang, 330006, Jiangxi, China
}

*For correspondence: Email: xiongjing328@hotmail.com; Tel/Fax: 0086-791-88692962

\begin{abstract}
Purpose: To investigate the expression levels of matrix metalloproteinases and their inhibitors in ulcerative colitis patients

Methods: In this investigation, the expression of matrix metalloproteinases (MMPs) and tissue inhibitors of metalloproteinases (TIMPs) were evaluated in 50 patients with ulcerative colitis, which comprised of 36 males and 14 females. The tissue samples were obtained from the core needle of sample and evaluated using immunochemistry techniques.

Results: The prevailing MMP-9 and TIMP-1 expressions in the glandular epithelium and inflammatory cells were observed. In addition, the expressions were coupled with architectural changes in the tissues and inflammation in the lamina propria. It was also observed that the expression of MMPs and inhibitors with weak activation established the progress of ulcerative colitis. Statistical correlation between the MMP expressions and histopathological parameters was also very significant. MMP expression correlated with weaker expression of TIMPs.

Conclusion: MMPs, especially MMP-2, MMP-7 and MMP-9, may provide a potential target for controlling ulcerative colitis.
\end{abstract}

Keywords: Ulcerative colitis, Matrix metalloproteinases, Tissue inhibitors of metalloproteinases, Lamina propria, Inflammation

Tropical Journal of Pharmaceutical Research is indexed by Science Citation Index (SciSearch), Scopus, International Pharmaceutical Abstract, Chemical Abstracts, Embase, Index Copernicus, EBSCO, African Index Medicus, JournalSeek, Journal Citation Reports/Science Edition, Directory of Open Access Journals (DOAJ), African Journal Online, Bioline International, Open-J-Gate and Pharmacy Abstracts

\section{INTRODUCTION}

Ulcerative colitis (UC) is a chronic form of inflammatory bowel disease (IBD) [1]. It usually remits inflammation in the large intestine [1]. It is also considered as an autoimmune disease influenced by environmental factors and genetic factors [2]. UC causes ulcer and inflammation in the colon in the large intestine. UC is a long lasting disease which starts in early adulthood and may last throughout life and existence of the disease is difficult to confirm until intestinal confirmation [3]. Moreover the incidence of ulcerative colitis has gradually increased in recent years with a higher rate of incidence in developed countries [4].

The symptoms of UC include diarrhea with blood, fever, abdominal pain and weight loss [5]. The cause of the disease is not properly understood, which is presumed a genetic risk. There are also certain reports which indicate the higher rate of $\mathrm{UC}$ is due to western lifestyle and diet [6]. The treatment of the disease includes the prescription of anti-inflammatory drugs and certain therapy, which targets the immune response specific mechanisms [7]. In severe cases of UC there is a need for the surgical removal of the large 
intestine partially or total which is called colectomy [8].

Matrix metalloproteinases (MMPs) belong to a group of proteolytic calcium-dependent enzyme which contains zinc, categorized under the metzincin superfamily $[9,10]$. These enzymes play an important role in the extracellular matrix protein degradation by cleaving its components such as cell surface receptors. In addition, these proteins are involved in processing certain bioactive molecules [11]. MMPs are also involved in proliferation of cell; cell adhesion and dispersion, programed cell death and cell differentiation [12]. MMPs are also regulated by cytokines and certain growth factors and hormones. They are also excreted by endothelial cells, neutrophils, macrophages, neutrophils and lymphocytes [13]. Four distinct domains comprise the three dimensional structure of MMPs - the catalytic domain, the pro-peptide domain, hinge region and haemopexin-like domain which is on the C-terminal $[9,14]$.

MMPs are known to have a common domain structure. These domains are the pro-peptide, the catalytic domain, and the haemopexin-like Cterminal domain, that is associated with the catalytic domain by a flexible hinge region. There are 26 types of MMPs which is categorized under six different sub groups [9]. MMPs are mostly controlled and inhibited by the tissue inhibitors of metalloproteinases (TIMPs) which comprise of TIMP-1, TIMP-2, TIMP-3, and TIMP-4 [15]. TIMPs usually have two domains that are functionally distinctive. For maintaining and remodeling of the cells and tissue functions there is a need for controlling the balance of MMPs and TIMPs. The imbalance of these proteins leads to disease such as tissue fibrosis, cardiovascular diseases and ulcers and tissue inflammations [15].

Thus, the present investigation aims on the evaluation of the immune-histochemical association with the Matrix Matalloprotienase (MMP-2, MMP-7 and MMP-9) and Tissue Inhibitors of Metalloproteinases (TIMP-1 and TIMP-2) in 50 cases of patients with ulcerative colitis and their correlation with histochemical and pathological parameters. The investigation will aid in understanding the expression of these proteins in ulcerative colitis which may provide a novel therapeutic target.

\section{METHODS}

The study was performed in compliance with the National Institutes of Health guidelines and was approved by the Local Bioethics Committee of
The First Affiliated Hospital of Nanchang University, Nanchang, Jiangxi, China. The present investigation consists of fifty patients $(\mathrm{N}$ $=50$ ) with 36 males and 14 females diagnosed with UC. All the patients were over 21 years of age. The biopsy samples were obtained from the core needle of sample which was further embedded with blocks of paraffin obtained from the Department of Gastroenterology and Surgery, Chinese Central Hospital, People RC.

All the reagents such as rabbit anti-Smad4, rabbit anti-Smad6, and rabbit anti-Smad7 monoclonal antibody of matrix metalloproteinase and mouse monoclonal antibody tissue inhibitor of matrix metalloproteinase 1 and 2 were purchased from Novocastra Reagents, Leica Microsystems, Germany. All the sections used in the present investigation were counter stained with hematoxylin and eosin (H\&E) with regular histopathological evaluation.

The tissue slides which were fixed with formalin and embedded in paraffin were cut using a $\mathrm{HM}$ 450 Sliding Microtome (Thermo Fisher Scientific, USA) with a thicker section of $4 \mu \mathrm{m}$. The sections were deparaffinized in xylene and rehydrated with alcohol. The sections of MMP-2 and TIMP-1 were further placed in a microwave oven for 30 min and treated with citrate buffer, then subjected to retrieval of the antigen using a pressure chamber. The slides were incubated with their corresponding primary antibodies for MMP-2, MMP-7, MMP-9, TIMP-1 and TIMP-2 respectively diluted to $1: 70$ and kept overnight at $4{ }^{\circ} \mathrm{C}$. The incubation continued for $20-30 \mathrm{~min}$ in their amplifying reagent at room temperature. The resulting antigen-antibody complex activity was detected and visualized using diaminobenzidine (DAB) and it was further counterstained with hematoxylin. The data analysis and correlation analysis for statistical significance was carried out using SPSS 18 statistical software. The $p$-value less than 0.05 were taken as statistically significant.

\section{RESULTS}

A total of 50 patients were analyzed in the present investigation of the patients with ulcerative colitis. Four cases of acute epithelial dysplasia were noticed, with 14 moderate cases and 20 indefinite cases. Twelve patients were noticed with negative or no grade of epithelial dysplasia (Table 1). In addition, the disease activity of ulcerative colitis was evaluated based on the protocol developed by Geboes et al [16] which indicated 30 subjects having chronic cases 
of UC, 8 active cases and 12 subjects with inactive UC (Table 1).

The expression analysis on glandular cells showed that, the expression of MMP-2 was weak in glandular epithelium in 60 cases covering 73.3 $\%$ of the patients having UC and in inflammatory cells covering $72 \%$ of the cases. The expression of MMP-2 was average and strong in the glandular tubes covering 16 and $8 \%$ of the case respectively, compared to 10 and $2 \%$ in the case of inflammatory cells respectively (Table 2 ).

On the contrary, the expression of MMP-7 protein was absent in 29 patients covering $58 \%$ of the cases in the glandular epithelium as opposed to the $6 \%$ of the cases in inflammatory cells. Also, $22 \%$ of the case has a weak expression of glandular cells compared to $36 \%$ of the inflammatory cells. $16.1 \%$ average expression and $32 \%$ of the cases have weak expression of MMP-9 in both the glandular cells and inflammatory cells. (Fig 1) (Table 2).

Furthermore, a strong expression of TIMP-1 was found in 32 cases covering $64 \%$ in the glandular epithelium. There were $40 \%$ of strong cases in cells of inflammatory infiltrates. While the reaction of TIMP-2 was higher in weak cases (44 $\%$ ) of glandular epithelium than in infiltration of inflammatory cells (33 \%) (Fig 2).

Table 1: Statistics of sex ratio, grade of dysplasia and disease activity

\begin{tabular}{llllllllll}
\hline Sex (N) & \multicolumn{4}{c}{ Grade of dysplasia (N) } & \multicolumn{3}{c}{ Disease activity (N) } \\
\hline Female & Male & Nil & \multicolumn{2}{c}{ Indefinite } & Moderate & Acute & Inactive & Active & Chronic \\
\hline 14 & 36 & 12 & 20 & 14 & 4 & 12 & 8 & 30 \\
\hline
\end{tabular}

$N=$ number

Table 2: MMP-2, MMP-7, and MMP-9 expression in glandular and inflammatory cells

\begin{tabular}{|c|c|c|c|c|c|c|c|c|}
\hline \multirow{3}{*}{$\begin{array}{l}\text { Protein } \\
\text { expression }\end{array}$} & \multicolumn{8}{|c|}{ Ulcerative colitis (UC) } \\
\hline & \multicolumn{4}{|c|}{ Glandular cells (\% of cases) } & \multicolumn{4}{|c|}{ Inflammatory cells (\% of cases) } \\
\hline & Absent & Weak & Mean & Strong & Absent & Weak & Mean & Strong \\
\hline MMP-2 & $2(4 \%)$ & $36(72 \%)$ & $8(16 \%)$ & $4(8 \%)$ & $8(16 \%)$ & $36(72 \%)$ & $5(10 \%)$ & $1(2 \%)$ \\
\hline MMP-7 & $29(58 \%)$ & $11(22 \%)$ & $9(9)$ & $1(2 \%)$ & $3(6 \%)$ & $18(36 \%)$ & $16(32 \%)$ & $13(26 \%)$ \\
\hline MMP-9 & $4(8 \%)$ & $16(32 \%)$ & $11(22 \%)$ & $19(38 \%)$ & $2(4 \%)$ & $16(32 \%)$ & $13(26 \%)$ & $19(38 \%)$ \\
\hline
\end{tabular}

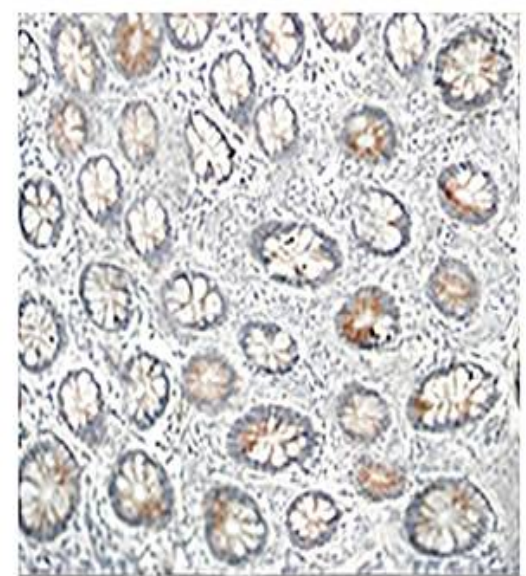

(a)

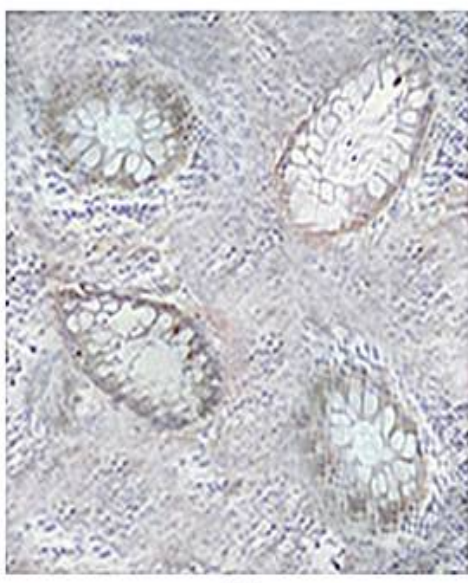

(b)

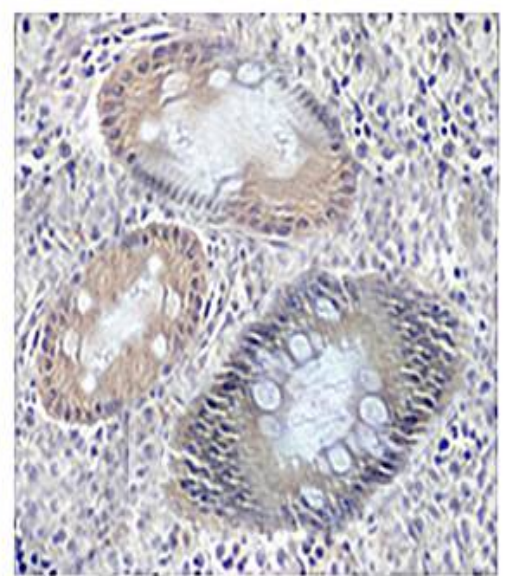

(c)

Figure 1: Immunohistochemical expression of MMP-2, MMP-7 and MMP-9 in glandular epithelium and inflammatory cells

Table 3: TIMP-1 and TIMP-2 expression in glandular and inflammatory cells

\begin{tabular}{|c|c|c|c|c|c|c|c|c|}
\hline \multirow{3}{*}{$\begin{array}{l}\text { Protein } \\
\text { Expres- } \\
\text { sion }\end{array}$} & \multicolumn{8}{|c|}{ Ulcerative colitis (UC) } \\
\hline & \multicolumn{5}{|c|}{ Glandular cells (\% of cases) } & \multicolumn{3}{|c|}{ Inflammatory cells (\% of cases) } \\
\hline & Absent & Weak & Mean & Strong & Absent & Weak & Mean & Strong \\
\hline TIMP-1 & $9(18 \%)$ & $7(14 \%)$ & $2(4 \%)$ & $32(64 \%)$ & $11(22 \%)$ & $16(32 \%)$ & $3(6 \%)$ & $20(40 \%)$ \\
\hline TIMP-2 & $4(8 \%)$ & $22(44 \%)$ & $15(30 \%)$ & $9(18 \%)$ & $20(42 \%)$ & $16(33 \%)$ & $4(8 \%)$ & $8(17 \%)$ \\
\hline
\end{tabular}




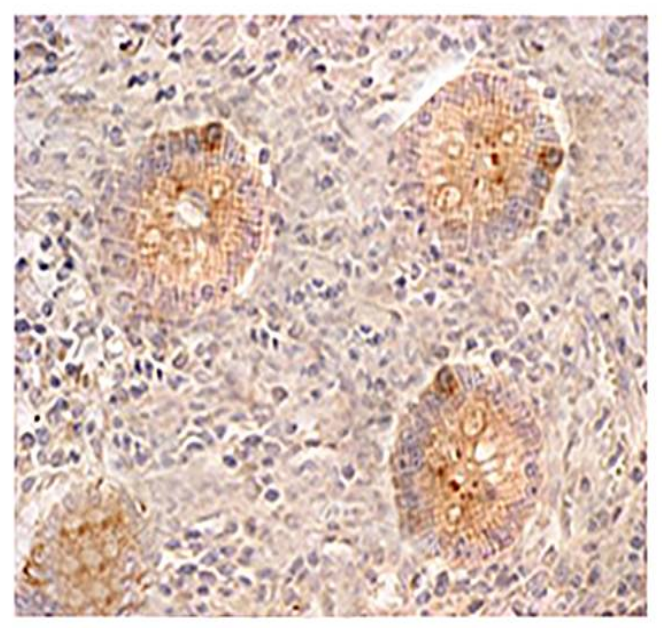

(e)

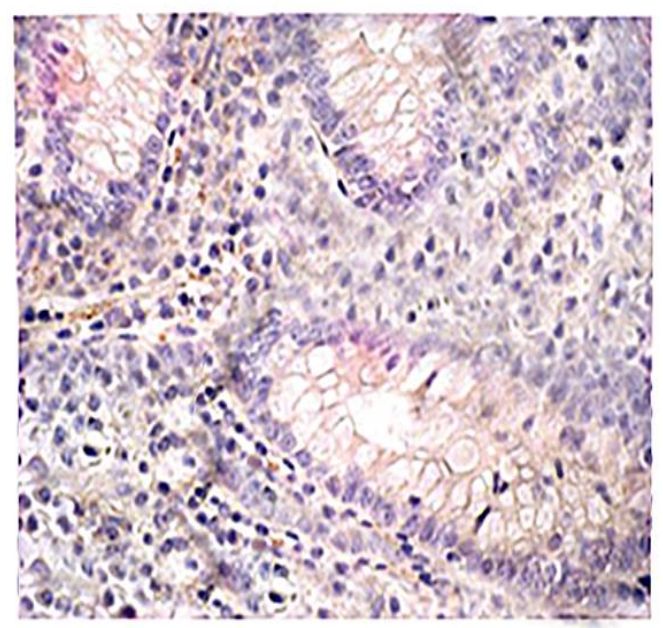

(d)

Figure 2: Immunohistochemical expression of TIMP-1 and TIMP-2 in glandular epithelium and inflammatory cells

The present investigation revealed a strong correlation with the expression of the MMPs in the glandular epithelium along with the presence of ulcers ( $p=0.051, \mathrm{R}=0.392)$. In addition, an increased trend was observed in the glandular epithelium of MMP-2 with a change in the architectural structure of the tissue $(p=0.076, \mathrm{R}$ $=0.381)$. The presence of neutrophils in the lamina propria is also observed $(p=0.077, \mathrm{R}=$ 0.371). (Fig 1a)

Considering MMP-7 expression in the glandular epithelium, most of the cases correlate with erosions $(p=0.031, \mathrm{R}=0.492)$. There was also a decrease in MMP-9 expression observed in the architectural tissue alterations $(p=0.067, \mathrm{R}=-$ 0.392 ) (Fig 1bc). The expression of MMP-2 in the propria of inflammatory infiltration correlated with the presence of neutrophils. In addition, the expression level of TIMP-1 corresponds with eosinophil in the lamina propria $(p=0.024, \mathrm{R}=$ $0.612)$ and neutrophils in glandular epithelium ( $p$ $=0.032, R=0.0581$ ). In addition, a significant correlation was observed in the expression of TIMP-2 in the glandular epithelium. However, no significant relationship was observed the case of TIMP-2 expression with the inflammatory cells (Fig 2).

\section{DISCUSSION}

In the present investigation, the expression of various metaloproteinase levels with their inhibitors was observed in various cases based on the stage and advancement. The study has shown that the expression on MMP-7 was weak in glandular epithelium in $60 \%$ of the cases which corresponds to inflammatory infiltration. The study also evidenced various destructive processes in the expression. However, some regenerative process was also observed in certain cases. The investigation also showed a weak expression of MMP-2 expression in the inflammatory infiltration contrasting a strong expression in the patients with glandular epithelium which has also been confirmed by von Lampe et al [17]. The study also noticed that MMP-2 expression is associated with erosions in the glandular epithelium. The expression of MMP-2 is also mainly associated with mesenchymal cells and neutrophils in the glandular epithelium and inflammatory infiltration. The investigation also observed an affirmative expression of MMP-9 both in glandular epithelium and inflammatory infiltration in which similar occurrence has been observed earlier in patients with ulcerative colitis [18]. Moreover, the protein activity was increased in ulcerative colitis by the homogeneity of the inflamed mucosa.

The statistical analysis in the present investigation showed that tissue architecture of the colon caused changes with increasing MMP9 expression. These observations provide an impetus for MMP-9 expression on the chronic inflammation of the tissue lining of the colons and remodeling of the tissue architecture. The present investigation also revealed that MMP-9 plays a crucial role in ulcerative colitis. In addition, there are various reports which support the pathogenesis of MMP-9 expression in colitis [19-20]. These findings may serve as a potential target for anti-inflammatory treatment. The expression of TIMP-1 and TIMP-2 also revealed that these proteins play a vital role in regulating the activity of the metalloproteinases thereby maintaining an equilibrium. In addition positive expression of TIMP-1 with an inflamed ulcer in ulcerative colitis has been reported earlier [21]. 


\section{CONCLUSION}

The expression of MMPs with the inhibitors that have weak activation establishes the progress of ulcerative colitis. Furthermore, the statistical correlation between MMPs expression with histopathological parameters is very significant. Thus, it may be deduced that MMPs, viz, MMP-2, MMP-7 and MMP-9 are potential targets for inhibitors such as TIMP-1 and TIMP-2 to reduce progression in ulcerative colitis in patients.

\section{DECLARATIONS}

\section{Acknowledgement}

The authors acknowledge support for this study from the First Affiliated Hospital of Nanchang University, Nanchang, 330006, Jiangxi, China.

\section{Conflict of Interest}

No conflict of interest associated with this work.

\section{Contribution of Authors}

The authors declare that this work was done by the authors named in this article and all liabilities pertaining to claims relating to the content of this article will be borne by them.

\section{Open Access}

This is an Open Access article distributed under the terms of the Creative Commons Attribution License, which permits unrestricted use, distribution, and reproduction in any medium, provided the original work is properly credited.

\section{REFERENCES}

1. Podolsky DK. Inflammatory bowel disease. N Engl J Med 2002; 347(6): 417-429.

2. Talley NJ, Abreu MT, Achkar JP, American College of Gastroenterology IBD Task Force. An evidence-based systematic review on medical therapies for inflammatory bowel disease. Am J Gastroenterol 2011; 106: S2-S25.

3. Pardi DS, Kelly CP. Microscopic colitis. Gastroenterol 2011; 140(4): 1155-1165.

4. Jiang XL, Cui HF. An analysis of 10218 ulcerative colitis cases in China. World J Gastroenterol 2002; 8(1): 158161.

5. Sawczenko A, Sandhu BK. Presenting features of inflammatory bowel disease in Great Britain and Ireland. Arch. Dis. Child. 2003; 88(1): 995-1000.
6. Hanauer SB, Sandborn W. Management of Crohn's disease in adults. Am. J. Gastroenterol. 2001; 96(3): 635-643.

7. Langan $R C$, Gotsch $P B$, Krafczyk MA, Skillinge $D D$. Ulcerative colitis: diagnosis and treatment. Am. Fam. Physician. 2007; 76(9): 1323-1330.

8. Baumgart DC, Sandborn WJ. Inflammatory bowel disease: clinical aspects and established and evolving therapies. The Lancet. 2007; 369(9573): 1641-1657.

9. Verma RP, Hansch C. Matrix metalloproteinases (MMPs): chemical-biological functions and (Q)SARs. Bioorg. Med. Chem. 2007; 15(6): 2223-2268.

10. Van $L P$, Libert $C$. Chemokine and cytokine processing by matrix metalloproteinases and its effect on leukocyte migration and inflammation. J. Leukoc. Biol. 2007; 82(6): 1375-1381.

11. Eisen A, Jeffrey J, Gross J. Human skin collagenase. Isolation and mechanism of attack on the collagen molecule. Biochim. Biophys. Acta. 1968; 151(3): 637645.

12. Gross J, Lapiere CM. Collagenolytic activity in amphibian tissues: a tissue culture assay". Proc. Natl. Acad. Sci. U $S$ A. 1962; 48(6): 1014-1022.

13. Pei $D$, Kang $T$, Qi $H$. Cysteine array matrix metalloproteinase (CA-MMP)/MMP-23 is a type II transmembrane matrix metalloproteinase regulated by a single cleavage for both secretion and activation. J. Biol. Chem. 2000; 275(43): 33988-33997.

14. Trexler M, Briknarová K, Gehrmann M, Llinás $M$, Patthy $L$. Peptide ligands for the fibronectin type II modules of matrix metalloproteinase 2 (MMP-2). J. Biol. Chem. 2003; 278(14): 12241-12246.

15. Trojanek J. Matrix metalloproteinases and their tissue inhibitors. Postepy. Biochem. 2012; 58(3): 353-362.

16. Geboes K, Riddell R, Ost A, Jensfelt $B$, Persson $T$, Löfberg $R$. A reproducible grading scale for histological assessment of inflammation in ulcerative colitis. Gut. 2000; 47(3): 404-409.

17. von Lampe B, Barthel B, Coupland SE, Riecken EO, Rosewicz S. Differential expression of matrix metalloproteinases and their tissue inhibitors in colon mucosa of patients with inflammatory bowel disease. Gut. 2000; 47(1): 63-73.

18. Mao JW, He XM, Tang HY, Wang YD. Protective role of metalloproteinase inhibitor (AE-941) on ulcerative colitis in rats. World J. Gastroenterol. 2012; 18(47): 70637069.

19. Medina C, Videla S, Radomski A, Radomski MW, Antolín $M$, Guarner F, Vilaseca J, Salas A, Malagelada JR. Increased activity and expression of matrix metalloproteinase-9 in a rat model of distal colitis. Am. J. Physiol. Gastrointest. Liver Physiol. 2003; 284(1): G116-G122.

20. Naito Y, Takagi T, Kuroda M. Katada K, Ichikawa $H$, Kokura S, Yoshida N, Okanoue T, Yoshikawa T. An orally active matrix metalloproteinase inhibitor, ONO4817, reduces dextran sulfate sodium-induced colitis in mice. Inflamm. Res. 2004; 53(9): 462-468.

Trop J Pharm Res, November 2016; 15(11): 2355 
Huang \& Xiong

21. Wang YD, Yan PY. Expression of matrix metalloproteinase-1 and tissue inhibitor of metalloproteinase-1 in ulcerative colitis. World $J$

Gastroenterol 2006; 12(37): 6050-6053. 